\title{
DESIGUALDADE DE OPORTUNIDADES NO BRASIL \\ Considerações sobre classe, educação e raça
}

\section{Pedro Ferreira de Souza \\ Carlos Antonio Costa Ribeiro \\ Flavio Carvalhaes}

\section{Introdução}

Pelo menos desde a década de 1940, quando Donald Pierson (1945) caracterizou o Brasil como uma "sociedade multirracial de classes", e principalmente a partir dos anos de 1950 , com a série de estudos sobre relações raciais patrocinados pela Unesco, consolidou-se em nosso país um longo debate sobre a importância relativa da estrutura de classes e das barreiras raciais na estruturação das nossas desigualdades. Nos últimos anos, especialmente com a discussão acerca das cotas em universidades públicas, o debate público e acadêmico retomou a questão com um foco mais restrito à desigualdade de oportunidades. Por trás da maioria dos discursos - acadêmicos e políticos - podemos distinguir claramente tentativas de responder à

Artigo recebido em setembro/2009

Aprovado em maio/2010 pergunta: as desigualdades de oportunidades são determinadas pelas barreiras de classe ou pelo preconceito racial?

Neste artigo, esperamos contribuir para uma melhor compreensão desta questão com base na análise da mobilidade social intergeracional no Brasil em 1982 e $1996 .{ }^{1}$ Embora haja críticas relevantes quanto à possibilidade de interpretar a associação intergeracional como uma medida unívoca do grau de igualdade de oportunidades (ver Swift, 2004), pensamos que esta associação ainda assim pode ser vista como uma proxy bastante satisfatória das desigualdades de oportunidades. Afinal, uma questão básica dos estudos de mobilidade social é a de como distinguir os efeitos dos diversos fatores que afetam a trajetória dos indivíduos. Técnicas e métodos cada vez mais sofisticados foram desenvolvidos para tentar medir, da melhor maneira possível, o impacto de variáveis que, na vida real, se encontram em geral estreitamente correlacionadas, 
como é o caso de classe e raça. Embora não tenhamos a pretensão de "resolver" quaisquer destas controvérsias, pensamos que uma análise detalhada dos padrões de mobilidade social do Brasil e que investigue os seus determinantes pode ser útil para fazer avançar o debate.

Assim, é preciso lembrar que as técnicas e os métodos estatísticos empregados em análises da mobilidade social sempre estiveram intimamente conectados às filiaçôes teóricas dos autores. As quatro "gerações" geralmente mencionadas nas revisões da literatura sobre mobilidade social (ver Treiman e Ganzeboom, 2000; Hendrickx e Ganzeboom, 1998; Silva, 1999, 2007; Dessens et al., 2003) têm divergências teóricas e metodológicas bem demarcadas. Por exemplo, Blau e Duncan (1967) e toda a tradição do status attainment, sob a influência do funcionalismo parsoniano, pensou a estratificação social como uma hierarquia contínua e unidimensional, empregando regressões lineares e modelos de análise de trajetória para avaliar a importância relativa de diversas variáveis para obtenção de status socioeconômico. Deixando de lado a preocupação da geração anterior acerca do grau de mobilidade entre gerações, essa tradição deu ênfase aos mecanismos de transmissão intergeracional de status, buscando identificar a transição da predominância de características herdadas para características adquiridas, que deveria culminar na institucionalização de um padrão universalista e meritocrático de mobilidade social. ${ }^{2}$

Por sua vez, a geração seguinte fez com que o pêndulo voltasse para a análise de classes. Por trás tanto das formulaçôes neoweberianas como das neomarxistas está a idéia de que o paradigma do status attainment centrado nas realizações individuais é inadequado para dar conta das divisões categóricas existentes no mundo produtivo, que fazem com que as relaçóes entre grupos sejam marcadas por diferenças substanciais de poder e recursos que têm conseqüências importantes para as chances de mobilidade intergeracional. Na prática, a operacionalização desta mudança só pôde avançar com o desenvolvimento de modelos log-lineares, que permitem separar efeitos marginais e de associação - ou seja, a fluidez social, entendida aqui como proxy da igualdade de oportunidades -, bem como a importância dos processos de imobilidade, aspectos negligenciados nos trabalhos de status attainment.

O preço disso foi a volta a análises essencialmente bivariadas. Por isso, os modelos logísticos multinomiais condicionais (LMC) introduzidos na sociologia por Logan (1983) foram saudados como representantes de uma nova geração de pesquisas por permitirem a conciliação das melhores características das análises anteriores, ainda que na literatura internacional relativamente poucos autores tenham empregado estes modelos (por exemplo, Breen, 1994; Hendrickx e Ganzeboom, 1998; Western, 1999; Dessens et al., 2003; no Brasil, Ribeiro, 2006). Na comparação entre modelos de diferentes gerações, a principal vantagem do uso dos modelos LMC apontadas por estes autores é a possibilidade de modelar adequadamente uma relação - entre origem e destino - que é complexa demais para ser expressa em um único parâmetro, o que permite inclusive a correção de estimativas possivelmente enviesadas geradas com base apenas em tabelas bivariadas. Este é precisamente o ponto que une os avanços metodológicos a certos refinamentos teóricos: a possibilidade de incluir inúmeras variáveis independentes com facilidade faz com que os estudos de mobilidade social possam avançar para além do estruturalismo mais ortodoxo sem, no entanto, abrir mão de uma perspectiva consistente acerca da estratificação social. Para os nossos propósitos isto é fundamental, pois permite testar o impacto da raça como uma variável independente e sua interação com a classe de origem, ao mesmo tempo em que levamos em consideração o grau de escolaridade dos indivíduos.

Diante desse quadro, para captar de forma mais robusta os determinantes da mobilidade social e suas tendências em 1982 e 1996, optamos pela análise tanto de modelos de regressão linear, que tomam a estratificação social como contínua e unidimensional, como de modelos LMC, que trabalham a diferenciação entre classes e permitem a inclusão de variáveis adicionais com facilidade. A comparação dos resultados nos permite testar sua robustez em relação aos métodos empregados. Com isso, esperamos contribuir para a consolidação de um campo de estudos que ainda é diminuto, especialmente diante da abundância de estudos que investigam a desigualdade de condiçôes propriamente 
dita (por exemplo, Ferreira e Barros, 1998; Ferreira e Litchfield, 2001; Ferreira et al., 2006; Barros et al., 2006a, 2006b, 2006c). Apesar de muitos destes trabalhos procurarem também avaliar quais seriam os determinantes da desigualdade de rendimentos, as características analisadas não incluem informaçōes acerca da origem social dos indivíduos, concentrando-se em variáveis como idade, educação, setor de atividade, regiáo geográfica e cor (por exemplo, Ramos e Vieira, 2001; Moura, 2008).

\section{Mobilidade, raça e fluidez social no Brasil ${ }^{3}$}

Os estudos mais recentes indicam de forma inequívoca que houve um aumento substancial da fluidez social no Brasil entre 1973 e 1996 (Pastore e Silva, 2000; Ribeiro e Scalon, 2001). No período em questáo, o coeficiente da associação entre origem e destino de classe diminuiu cerca de $16 \%$ para os homens e $23 \%$ para as mulheres (Ribeiro, 2007). A diminuição da associação origem-destino não parece ser um padrão exclusivo do nosso país: também na literatura internacional podemos encontrar vários exemplos de fluidez crescente ao longo do tempo (ver Hout, 1988; sobre os Estados Unidos, Alemanha, França, Itália, Irlanda, Suécia, Noruega, Polônia, Hungria e Holanda, ver Breen, 2004), contrariando a famosa hipótese de Erikson e Goldthorpe (1992) sobre a estabilidade dos padrōes de fluidez social nas sociedades industriais.

Sabemos também que o aumento da fluidez social no Brasil se deu por um efeito de período, e não pela substituição de coortes - como na Alemanha e na Suécia (Breen e Jonsson, 2007; Breen e Luijkx, 2007) -, tendo como mecanismo principal a diminuição dos retornos para a educação, por oposiçãao à equalização educacional (Ribeiro e Torche, 2010). Além disso, Barros et al. (2006b) também identificaram recentemente uma diminuição dos retornos em renda para a educação, que foi responsável por cerca de $20 \%$ da queda da desigualdade da renda do trabalho entre 2001 e 2005.

No que diz respeito à relação entre classe de origem, raça e classe de destino, Ribeiro (2006) resume as quatro hipóteses principais da literatura: a primeira, derivada dos argumentos de Pierson (1945) e Azevedo (1996), dá primazia às barreiras de classe, esvaziando a importância do preconceito de raça, afirmando que os pretos e os pardos estão na base da pirâmide social apenas em função da proximidade temporal com o regime escravocrata, mas que isso se diluiria em poucas geraçôes; a segunda hipótese, presente em Costa Pinto (1952) e, de certa maneira, em Nogueira (1998), prevê que, embora a modernização faça com que as divisões de classe se tornem mais centrais, o aumento da mobilidade social dos não-brancos seria visto como uma ameaça pelos grupos dominantes, o que acirraria as discriminaçōes raciais. Já a terceira hipótese seria a de Florestan Fernandes (1965) e seus discípulos, para quem a estratificação por cor ou raça, embora realmente existente, teria um caráter residual, ligado à herança colonial, e, assim, tenderia a perder importância para as barreiras de classe na medida em que o país se modernizasse. Por fim, a quarta e última hipótese seria a levantada por Hasenbalg (1979) e Silva (1978), que sugerem que a estratificação racial não pode ser reduzida a um epifenômeno da estratificação por classe e que ambas permaneceriam influentes - e relativamente independentes - mesmo com a consolidação da sociedade industrial no Brasil.

Boa parte dos estudos quantitativos que procuraram testar estas hipóteses limitou-se a analisar os percentuais de tabelas cruzadas, carecendo de modelos robustos que fossem capazes de controlar as distribuiçôes marginais (por exemplo, Hasenbalg, 1979 e 1988; Hasenbalg e Silva, 1988). Silva (1988) contornou o problema ao utilizar um modelo de regressão linear de status attainment, constatando grandes interaçōes com a cor ou raça: não apenas não-brancos tinham menos anos de escolaridade em média do que os brancos como, principalmente, os retornos para cada ano eram maiores para esses últimos, o que sustentaria a quarta hipótese, que versa sobre as desvantagens cumulativas que impactam o ciclo de vida dos pretos e pardos.

Quase todos os trabalhos recentes utilizam modelos $\log$-lineares e afins para analisar tabelas cruzadas de origem e destino, ocasionalmente acrescentado variáveis adicionais. Assim, Osório (2003) encontra diferenças significativas nas chances relativas de mobilidade entre brancos e não-brancos, 
apontando, ainda, a presença de uma interação entre classe de origem e raça ou cor. Ribeiro (2006), por sua vez, chega a resultados parecidos, mas, ao empregar modelos log-lineares e logísticos multinomiais condicionais, conclui que as barreiras raciais parecem só ter peso significativo quando se trata da ascensão às classes mais privilegiadas. Assim, para este autor, seriam necessárias novas sínteses teóricas sobre a relação entre classe, raça e mobilidade social, embora seus achados tenham, em certa medida, uma forma de parentesco com a hipótese de Costa Pinto (1952), que problematizava especificamente a questão da entrada dos não-brancos nas classes dominantes. Finalmente, Osório (2009) demonstra que os padrões de mobilidade de renda de brancos e negros são muito semelhantes e majoritariamente de curta distância e que a origem social é o principal fator de reprodução da desigualdade racial de renda devido a seu impacto na realização educacional dos indivíduos. Apesar disso, o autor destaca que a discriminação racial tem um papel importante: em um regime de baixa mobilidade sem viés racial, a tendência de longo prazo seria a lenta equalização entre os grupos, mas as desigualdades raciais praticamente não se alteraram nos últimos trinta anos do século passado. Assim, a discriminação racial, embora não seja o fator principal, seria um freio que garantiria a estabilidade das desigualdades.

Em suma, os trabalhos anteriores apontam para a necessidade de uma consideração minuciosa da influência da origem social, da cor ou raça e da interação entre ambas em um contexto de fluidez social crescente e de retornos decrescentes para a educação. $\mathrm{O}$ único deles que empregou os métodos mais recentes foi o de Ribeiro (2006) e, mesmo assim, apenas para o ano de 1996. Pretendemos aqui realizar uma análise mais exaustiva tanto em função dos métodos como do corte temporal adotado.

\section{Dados e métodos}

As análises neste artigo foram feitas com base nas Pnads 1982 e 1996, tendo sido selecionados apenas os indivíduos ocupados, com idades entre 25 e 64 anos, moradores das regiōes Sudeste e Nordeste do Brasil, ${ }^{4}$ o que resultou em um total de quase
110 mil casos. Para obter estimativas mais refinadas, separamos neste trabalho a mobilidade social de homens e mulheres, uma vez que há diferenças importantes de gênero nas trajetórias ocupacionais.

Dessa forma, aplicamos regressões lineares de status attainment e modelos logísticos multinomiais condicionais (LMC) separadamente a subamostras de homens e mulheres. Nas regressóes lineares, as posições socioeconômicas do respondente e do seu pai são medidas pelo índice socioeconômico internacional (Isei), desenvolvido por Ganzeboom et al. (1992) e largamente utilizado em trabalhos da área. A escala Isei varia de 16 a 90, e foi elaborada a partir da idéia de que a ocupação é o mecanismo interveniente entre educação e renda, distinguindose, portanto, das escalas de prestígio.

No modelo LMC, o esquema utilizado para as classes de origem e destino foi uma versão adaptada do assim chamado esquema EGP, desenvolvido por Goldthorpe e seus associados (ver Erikson e Goldthorpe, 1992; Goldthorpe, 2000). ${ }^{5}$ Dada a complexidade dos modelos, optamos por limitar as categorias ocupacionais a oito, mantendo as principais distinções feitas por Goldthorpe e acrescentando uma outra distinção especificamente importante no contexto brasileiro, inspirada pelos grupos de status de Silva (2003): os trabalhadores manuais qualificados da indústria moderna foram separados dos demais trabalhadores manuais qualificados, em função da posição específica do primeiro grupo nas condições de industrialização da sociedade brasileira. A Tabela 1 mostra o tamanho proporcional das classes de destino e as médias da escala Isei para cada classe. Vemos que a distribuição de homens e mulheres pela estrutura de classes segue padrões bastante distintos.

Foram usados dois refinamentos aplicáveis a modelos LMC, que são úteis por tornar a interpretação mais fácil: o primeiro é o modelo RC2 desenvolvido por Goodman (1979) para análises log-lineares, que estima uma métrica tanto para a variável dependente categórica como para a independente categórica (ou seja, as classes de destino e origem), permitindo que o efeito de uma sobre a outra seja expresso por um único parâmetro. Logo, os modelos aqui utilizados diferem dos de Goldthorpe, que rejeita qualquer ordenamento linear das classes. 
Tabela 1

Tamanho percentual das classes de destino e médias de Isei por classe, indivíduos ocupados de 25 a 64 anos, regióes Sudeste e Nordeste, casos selecionados, Pnads 1982 e 1996

\begin{tabular}{|c|c|c|c|}
\hline \multirow[t]{2}{*}{ Homens } & \multicolumn{2}{|c|}{$\%$ de casos } & \multirow{2}{*}{$\begin{array}{l}\text { Isei médio }^{6} \\
1982-1996\end{array}$} \\
\hline & 1982 & 1996 & \\
\hline Profissionais e administradores & 7,5 & 8,2 & 67 \\
\hline Trabalhadores não manuais de rotina & 8,8 & 10,4 & 42 \\
\hline Proprietários com empregados & 4,3 & 4,6 & 58 \\
\hline Proprietários sem empregados & 3,9 & 5,9 & 28 \\
\hline $\begin{array}{l}\text { Técnicos e supervisores do trabalho manual e trabalhadores } \\
\text { manuais qualificados da indústria moderna }\end{array}$ & 10,6 & 10,3 & 38 \\
\hline $\begin{array}{l}\text { Trabalhadores manuais qualificados da indústria tradicional e } \\
\text { dos serviços }\end{array}$ & 11,3 & 11,3 & 30 \\
\hline Trabalhadores manuais não qualificados & 23,0 & 24,1 & 29 \\
\hline $\begin{array}{l}\text { Trabalhadores rurais e proprietários rurais com e sem } \\
\text { empregados }\end{array}$ & 30,4 & 25,3 & 18 \\
\hline \multirow[t]{2}{*}{ Mulheres } & \multicolumn{2}{|c|}{$\%$ de casos } & Isei médio \\
\hline & 1982 & 1996 & 1982-1996 \\
\hline Profissionais e administradores & 5,9 & 7,6 & 68 \\
\hline Trabalhadores não manuais de rotina & 20,6 & 22,0 & 50 \\
\hline Proprietários com empregados & 1,4 & 2,4 & 57 \\
\hline Proprietários sem empregados & 4,3 & 5,0 & 27 \\
\hline $\begin{array}{l}\text { Técnicos e supervisores do trabalho manual e trabalhadores } \\
\text { manuais qualificados da indústria moderna }\end{array}$ & 0,9 & 1,1 & 46 \\
\hline $\begin{array}{l}\text { Trabalhadores manuais qualificados da indústria tradicional e } \\
\text { dos serviços }\end{array}$ & 16,4 & 12,1 & 39 \\
\hline Trabalhadores manuais não qualificados & 30,8 & 27,1 & 21 \\
\hline $\begin{array}{l}\text { Trabalhadores rurais e proprietários rurais com e sem } \\
\text { empregados }\end{array}$ & 19,4 & 22,6 & 17 \\
\hline
\end{tabular}

Pensamos que esta é a melhor opção não só pelo aspecto prático, mas também pelo fato de que os modelos topológicos utilizados por ele tendem a subestimar os efeitos da hierarquia nas chances de mobilidade (Hout e Hauser, 1992). Como estamos operando apenas com oito categorias e, portanto, com distinçôes mais fortes entre elas, acreditamos que a hierarquização linear é robusta para os nossos dados. O segundo refinamento adotado é o uso do modelo de regressão ordenada estereotipada (Stereotyped Ordered Regression, SOR), desenvolvido por Anderson (1984) e DiPrete (1990), que estima uma métrica para a variável dependente e, assim, pode dar conta de todos os contrastes com apenas um único parâmetro para as demais variáveis independentes. Uma pressuposição para o uso do modelo SOR é o de que os efeitos das variáveis independentes na classe de destino são comparáveis, 
isto é, todas atuam na mesma direção. Juntos, os modelos SOR e RC2 simplificam enormemente o número de parâmetros estimados e, assim, tornam as interpretações mais inteligíveis.?

Por fim, as demais variáveis explicativas incluídas em ambos os modelos - regressão linear e LMC - são essencialmente as mesmas. Para cor ou raça, empregamos dummies para brancos e pardos, mantendo os pretos como categoria de referência, o que nos permite testar se a dicotomia brancos/não-brancos normalmente utilizada é, neste caso, empiricamente justificável.

Para dar conta do efeito não linear da educação, optamos por utilizar cinco variáveis baseadas nos ciclos escolares tradicionais, ${ }^{8}$ tomando os indivíduos sem nenhuma escolaridade como categoria de referência, de acordo com a Tabela 2.

\section{Fluidez e mobilidade social dos homens}

Entre os possíveis modelos de status attainment, testamos e descartamos modelos com variáveis de região, experiência e idade, bem como as interaçôes entre cor e educação e cor e Isei do pai. O fato de essas interaçôes não se mostrarem relevantes indica que os retornos para educação, pelo menos quando medidos desta maneira, são idênticos para brancos, pardos e pretos. A Tabela 3 exibe os resultados para o modelo final proposto.

O decisivo para a realização de status é a educação. A inclusão dos controles relativos à área, à cor e ao Isei paterno melhora o ajuste do modelo - em contraponto ao modelo que contempla apenas a educação - em cerca de 5\%. Destes controles, somente a dummy para áreas urbanas tem impacto relevante. Além disso, não podemos afirmar com segurança que o efeito do Isei do pai e da cor ou raça mudou entre 1982 e 1996 . Por outro lado, parece haver, de fato, uma queda dos retornos para educação em todos os níveis, sendo particularmente forte para aqueles que só completaram o primário e que só completaram o ensino fundamental: levando em conta os intervalos de confiança, os retornos para o primário declinaram entre $20 \%$ e $37 \%$, para o Ensino Fundamental, entre 28\% e 40\%. Os retornos para o Ensino Médio diminuíram entre 17\% e 26\%, para o Ensino Superior, de 5\% a 11\%. $\mathrm{Na}$ prática, estes números indicam a diminuição da distância que separa a categoria de referência e todos os níveis educacionais em termos de Isei, mas que ela se deu com força particular nos estratos educacionais intermediários e inferiores, os quais perderam seu poder de distinção.

Outro resultado importante é que o processo de realização de status se tornou mais incerto em relação às variáveis incluídas: isto fica evidente na queda de $12 \%$ do $\mathrm{R}^{2}$ ajustado. Há um aspecto positivo nesta queda, já que isso implica que a realização de status está sendo menos estruturada por desigualdades raciais, de origem social e de área de moradia, dificilmente encaradas como defensáveis ou justas. Por outro lado, as quedas mais pronunciadas foram dos retornos educacionais, num processo que pode ser lido tanto na chave da destruição saudável de rents educacionais (Sorensen, 2005) e aumento de oportunidades, como na chave mais pessimista de enfraquecimento de um mecanismo meritocrático de ascensão social. Não sabemos, no entanto, se esta desestruturação reflete uma individualização de fato das desigualdades (ou seja, fatores como sorte, acaso e afins ganham importância relativa) ou se estamos diante de uma situação na qual há maior importância de outras variáveis não incluídas no modelo.

Quanto ao impacto da origem social e da cor ou raça, podemos dizer, no máximo, que ele é muito limitado quando controlamos pela educação e que não é possível afirmar de forma conclusiva que tenha havido mudanças entre 1982 e 1996. Somente a origem social parece ter algum impacto direto mais forte no status dos respondentes e, mesmo assim, apenas em situações extremas. Os resultados sugerem, portanto, que o efeito mais forte da cor e da origem provavelmente se dá justamente nos processos de aquisição de escolaridade, e não na trajetória dentro do mercado de trabalho propriamente dito.

$\mathrm{Na}$ análise do modelo LMC, a Tabela 4 mostra estatísticas de ajuste para vários modelos. Com base na idéia de que classe, raça e educação são variáveis fundamentais para a compreensão dos processos de mobilidade social, empreendemos uma análise exploratória empiricamente orientada: começamos 
Tabela 2

Variáveis educacionais utilizadas, anos de estudo correspondentes e composição da amostra em 1982 e 1996 (homens e mulheres)

\begin{tabular}{llll}
\hline Nível educacional & Anos de estudo & \% em 1982 & \% em 1996 \\
\hline Nenhuma escolaridade & 0 & 31,9 & 19,5 \\
\hline Fez parte do primário & De 1 a 3 & 21,4 & 17,1 \\
\hline Primário completo & De 4 a 7 & 26,1 & 28,3 \\
\hline Ensino Fundamental completo & De 8 a 10 & 6,5 & 11,6 \\
\hline Ensino Médio completo & De 11 a 14 & 8,5 & 15,3 \\
\hline Ensino Superior completo & 15 ou mais & 5,7 & 8,2 \\
\hline
\end{tabular}

Tabela 3

Modelo proposto da regressão de status attainment para homens

\begin{tabular}{|c|c|c|c|c|}
\hline & 1982 & & 1996 & \\
\hline & Coeficientes & Erro padrão & Coeficiente & Erro padrão \\
\hline Constante & 15,32 & 0,20 & 15,92 & 0,32 \\
\hline Isei do pai & 0,11 & 0,00 & 0,12 & 0,01 \\
\hline Brancos & 2,05 & 0,19 & 1,67 & 0,28 \\
\hline Pardos & 0,88 & 0,19 & $0,35^{*}$ & 0,29 \\
\hline Área urbana & 7,49 & 0,12 & 6,45 & 0,18 \\
\hline Só fez parte do primário & 2,96 & 0,14 & 2,37 & 0,23 \\
\hline Primário & 7,46 & 0,14 & 5,25 & 0,21 \\
\hline Ensino Fundamental & 14,23 & 0,23 & 9,29 & 0,27 \\
\hline Ensino Médio & 21,28 & 0,23 & 16,65 & 0,27 \\
\hline Ensino Superior & 36,93 & 0,27 & 33,97 & 0,34 \\
\hline $\mathrm{R}^{2}$ ajustado & 0,572 & & 0,507 & \\
\hline $\begin{array}{l}\mathrm{R}^{2} \text { ajustado, modelo com } \\
\text { educação omitida }\end{array}$ & 0,364 & & 0,298 & \\
\hline $\begin{array}{l}\mathrm{R}^{2} \text { ajustado, modelo } \\
\text { apenas com educação }\end{array}$ & 0,525 & & 0,470 & \\
\hline
\end{tabular}

* Não significativo a 0,05 . 
com o modelo mais simples - basicamente um modelo log-linear com um parâmetro de imobilidade para cada classe e a mesma escala RC2 para origem e destino (eqRC2) - e, a partir daí, testamos os efeitos da inclusão das variáveis de interesse, que são as duas dummies de cor (brancos e pardos), as cinco dummies educacionais e suas possíveis interaçôes. Assim, nesta tabela, cada linha repete o modelo da linha anterior acrescentando as variáveis listadas, sendo o modelo 7 o mais complexo de todos, uma vez que inclui um parâmetro para investigar se há uma interação entre classe de origem e níveis altos de escolaridade, o que sugeriria a importância de mecanismos de distinção por meios de capital cultural ou social obtido na família de origem. Contudo, esta interação não é estatisticamente significativa.

Valores negativos da estatística BIC indicam que o modelo mais parcimonioso é mais adequado, ao passo que valores positivos indicam como melhor o modelo mais complexo. No caso, tanto para 1982 como para 1996, o modelo que combina melhor ajuste e parcimônia é aquele que não contém intera-

Tabela 4

Estatísticas de ajuste do modelo LMC para homens

1982

\begin{tabular}{lllll}
\hline & Log-Likelihood & L $^{2}$ vs modelo $7^{*}$ & Df vs modelo 7 & BIC** \\
\hline 1. Quasi-eqRC2 & -77882 & 16143 & 21 & 15878 \\
\hline 2. Brancos, pardos e educação & -69828 & 35 & 14 & -141 \\
\hline 3. Interação origem/brancos & -69828 & 35 & 13 & -129 \\
\hline 4. Interação origem/pardos & -69826 & 31 & 12 & -120 \\
\hline 5. Interação brancos/educação & -69814 & 7 & 7 & -81 \\
\hline $\begin{array}{l}\text { 6. Interação pardos/educação } \\
\text { 7. Interação origem/ensino médio completo e } \\
\text { origem* nível superior completo }\end{array}$ & -69812 & 2 & 2 & -23 \\
\hline
\end{tabular}

1996

\begin{tabular}{lllll}
\hline & Log-Likelihood & L2 vs modelo 6 & Df vs modelo 6 & BIC \\
\hline 1. Quasi-eqRC2 & -49209 & 8379 & 21 & 8123 \\
\hline 2. Brancos, pardos e educação & -45061 & 82 & 14 & -88 \\
\hline 3. Interação origem/brancos & -45059 & 79 & 13 & -80 \\
\hline 4. Interação origem/pardos & -45056 & 72 & 12 & -74 \\
\hline 5. Interação brancos/educação & -45045 & 50 & 7 & -36 \\
\hline $\begin{array}{l}\text { 6. Interação pardos/educação } \\
\text { 7 Interação origem/ensino médio completo e } \\
\text { origem/nível superior completo }\end{array}$ & -45040 & 39 & 2 & 15 \\
\hline
\end{tabular}

* A estatística L2 é calculada da maneira tradicional: $2^{*}(112$ - 1l1), onde 112 é o log-likelihood do modelo mais complexo e 111 é o da versão mais parcimoniosa.

** Quando as amostras são grandes, os testes do qui-quadrado para a estatística L2 quase sempre rejeitam os modelos mais simples, mesmo que o efeito das variáveis adicionais seja pouco relevante. Para contornar este problema, Raftery $(1986,1995)$ desenvolveu a estatística BIC, definida pela fórmula $\mathrm{L}^{2}-\mathrm{df}^{*} \ln (\mathrm{N})$, onde $\mathrm{L}^{2}$ é o da diferença entre dois modelos aninhados; $\mathrm{DF}$, a diferença de graus de liberdade entre ambos; e $\mathrm{N}$, o tamanho da amostra. 
çôes. Logo, nem a associação entre origem e destino nem os retornos para educação parecem diferir de forma significativa entre brancos, pardos e pretos. Também não pudemos detectar efeitos relevantes da interação entre origem e altos níveis educacionais. No modelo escolhido, a classe de destino é afetada pela classe de origem, pela cor e pela educação dos indivíduos, com a mesma escala para origem e destino e sem interações entre as variáveis independentes. Como as escalas eqRC2 separadamente para 1982 e 1996 mantêm a mesma hierarquia e atribuem valores quase idênticos às classes, optamos por unir os dois bancos de dados e incluir variáveis para dar conta da mudança dos coeficientes ao longo do tempo, o que facilita a interpretação. O Gráfico 1 ilustra a escala eqRC2 final, que varia de 0 (profissionais e administradores) a 1 (trabalhadores rurais), e é sociologicamente congruente. ${ }^{9}$

Por fim, a Tabela 5 resume as demais informações do modelo. Os painéis A e B contêm parâmetros para a imobilidade de classe. Em ambos, a interpretação segue a mesma lógica dos modelos log-lineares: basta calcular o anti-log do parâmetro para obter as chances de imobilidade de cada classe. O painel $\mathrm{C}$ traz as informaçóes acerca da associação origem-destino. Para obter razôes de chance facilmente interpretáveis, basta multiplicar o parâmetro pela distância RC2 entre duas classes de origem e pela distância entre duas classes de destino, e depois calcular o anti-log. Por exemplo, $(1,575)^{*}(0-0,290) *(0-0,290)=0,136$ e $\exp (0,136)$ $=1,146$, ou seja, em 1982, um filho de profissional ou administrador tinha 1,146 vezes mais chances de ser profissional e não trabalhador não manual de rotina do que um filho de trabalhador não manual de rotina. Por fim, o painel D contém os dados para as demais variáveis independentes. O cálculo das chances segue uma lógica parecida com a anterior: basta multiplicar o parâmetro pela distância entre as classes de destino, cujo contraste nos é interessante.

Do ponto de vista da imobilidade, a classe com maior propensão à reprodução é a de trabalhadores rurais. Em seguida vêm as classes proprietárias, cuja trajetória variou no período: enquanto a imobilidade diminuiu na classe dos empregadores, as mudanças entre os proprietários sem empregadores não foram significativas. A outra classe, cuja propensão à imobilidade oscilou de maneira importante, foi a dos técnicos e dos trabalhadores manuais qualificados da indústria moderna, cuja imobilidade predita caiu quase $30 \%$. Esta queda da tendência à imobilidade foi acompanhada também de uma piora

\section{Gráfico 1 \\ Escala eqRC2 para Homens, 1982/1996}

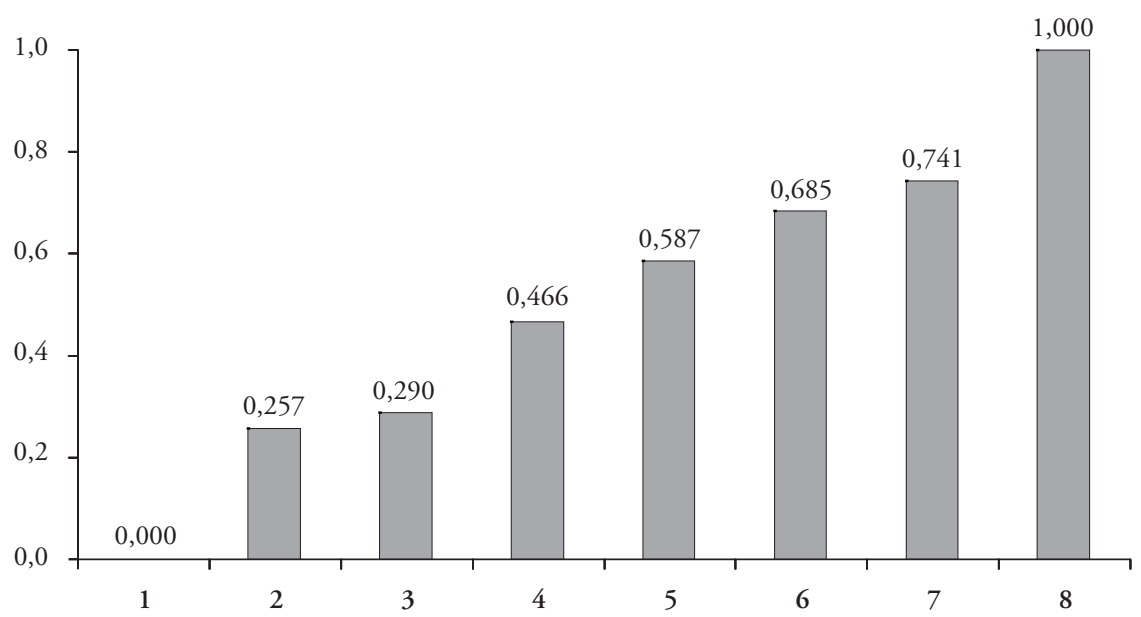

Obs.: 1 - Profissionais e administradores; 2 - Proprietários empregadores; 3 - Trabalhadores não manuais de rotina; 4 - Técnicos e supervisores do trabalho manual e trabalhadores manuais qualificados da indústria moderna; 5 - Proprietários sem empregados; 6 - Trabalhadores manuais não qualificados; 7 - Trabalhadores manuais qualificados da indústria tradicional e serviços; 8 - Proprietários rurais, produtores agrícolas autônomos e trabalhadores rurais em geral. 
Tabela 5

Parâmetros do modelo LMC para homens, 1982/1996

A: Imobilidade em 1982

\begin{tabular}{|c|c|c|}
\hline & Coeficiente & Erro padrão \\
\hline Profissionais e administradores & $0,043^{*}$ & 0,078 \\
\hline Proprietários empregadores & 1,125 & 0,065 \\
\hline Trabalhadores não manuais de rotina & 0,397 & 0,063 \\
\hline $\begin{array}{l}\text { Técnicos e supervisores do trabalho manual e trabalhadores } \\
\text { manuais qualificados da indústria moderna }\end{array}$ & 0,961 & 0,055 \\
\hline Proprietários sem empregados & 1,037 & 0,075 \\
\hline Trabalhadores manuais não qualificados & 0,348 & 0,036 \\
\hline $\begin{array}{l}\text { Trabalhadores manuais qualificados da indústria tradicional e } \\
\text { dos serviços }\end{array}$ & 0,737 & 0,046 \\
\hline Trabalhadores rurais & 1,440 & 0,040 \\
\hline \multicolumn{3}{|l|}{ B: Imobilidade em 1996} \\
\hline & Coeficiente & Erro padrão \\
\hline Profissionais e administradores & 0,250 & 0,084 \\
\hline Proprietários empregadores & 0,831 & 0,100 \\
\hline Trabalhadores não manuais de rotina & 0,435 & 0,063 \\
\hline $\begin{array}{l}\text { Técnicos e supervisores do trabalho manual e trabalhadores } \\
\text { manuais qualificados da indústria moderna }\end{array}$ & 0,608 & 0,058 \\
\hline Proprietários sem empregados & 1,209 & 0,082 \\
\hline Trabalhadores manuais não qualificados & 0,387 & 0,038 \\
\hline $\begin{array}{l}\text { Trabalhadores manuais qualificados da indústria tradicional e dos } \\
\text { serviços }\end{array}$ & 0,841 & 0,048 \\
\hline Trabalhadores rurais & 1,560 & 0,044 \\
\hline \multicolumn{3}{|l|}{ C: Associação origem-destino } \\
\hline & Coeficiente & Erro Padrão \\
\hline Associação geral & 1,575 & 0,119 \\
\hline Associação/ano & $-0,079 *$ & 0,179 \\
\hline \multicolumn{3}{|l|}{ D: Demais variáveis independentes } \\
\hline & Coeficiente & Erro padrão \\
\hline Brancos & $-0,778$ & 0,088 \\
\hline Brancos/ano & $0,204^{*}$ & 0,145 \\
\hline Pardos & $-0,015^{*}$ & 0,090 \\
\hline Pardos/ano & $0,139^{*}$ & 0,149 \\
\hline
\end{tabular}




\begin{tabular}{lll}
\hline Só fez parte do primário & $-2,379$ & 0,067 \\
\hline Só fez parte do primário/ano & 0,386 & 0,122 \\
\hline Completou o primário & $-4,630$ & 0,070 \\
\hline Completou o primário/ano & 0,863 & 0,119 \\
\hline Completou o ensino fundamental & $-6,748$ & 0,101 \\
\hline Completou o ensino fundamental/ano & 1,436 & 0,152 \\
\hline Completou o Ensino Médio & $-8,471$ & 0,106 \\
\hline Completou o Ensino Médio/ano & 1,357 & 0,155 \\
\hline Nível superior completo & $-12,722$ & 0,156 \\
\hline Nível superior completo/ano & 2,041 & 0,212 \\
\hline Ano & $-0,228^{*}$ & 0,222 \\
\hline
\end{tabular}

*Não significativo a 0,05 .

na sua posição relativa quanto à renda: enquanto a média da renda horária real do trabalho teve um crescimento de quase 30\% entre 1982 e 1996, a renda média real desta classe aumentou apenas $6 \%$, o menor aumento entre as oito classes de nossa tipologia. ${ }^{10}$ Esses dados não são de todo surpreendentes, pois, como se trata de um setor atingido de forma particularmente forte pela crise dos anos de 1980 e pela reestruturação produtiva da década seguinte, apenas traduzem em números parte das conclusões da sociologia do trabalho no Brasil (ver Cardoso, 1999; Castro e Dedecca, 2001). Cabe notar, ainda, que, quando se faz o controle por cor e educação, a imobilidade entre os profissionais e administradores praticamente desaparece. Mais do que para qualquer outra classe, a via de entrada privilegiada é pela educação.

Passando para o painel C, vemos que a associação origem-destino não teve mudanças relevantes entre 1982 e 1996 quando controlamos por cor e educação, o que reforça a idéia já apresentada de que a maior fluidez social identificada em muitos estudos está mais ligada a mudanças relativas a outras variáveis, como a diminuição dos retornos para a educação.

Com o coeficiente de associação e a escala eqRC2 podemos calcular todas as razões de chances desejadas. Quanto maior a distância na escala eqRC2 entre duas classes de origem, maior a diferença nas chances de ter um melhor destino de classe. Vale observar que a magnitude e o comportamento do coeficiente de associação são bem diferentes quando comparamos com um modelo que leva em conta apenas origem e destino, sem as demais variáveis independentes: ao acrescentar cor e níveis educacionais, o coeficiente de associação origem-destino cai cerca de $70 \%$ tanto em 1982 como em 1996, o que indica que estes são mecanismos de mediação importantes e que o grande gargalo está no acesso diferenciado à educação.

Por fim, no painel D observamos que, assim como no modelo de regressão linear, o peso das variáveis educacionais é enorme e que apenas estas variáveis experimentaram mudanças significativas ao longo do período: os coeficientes para todos os níveis são menores em 1996 do que em 1982, ilustrando a diminuição dos retornos para a educação. A diminuição dos efeitos da cor não é significativa ao longo do tempo e, pelo menos no que diz respeito à mobilidade social, dividir a população entre brancos e não-brancos é empiricamente justificável.

Para comparar os efeitos de cor e origem, não podemos simplesmente olhar para os parâmetros estimados: para origem, o impacto é calculado pela multiplicação do coeficiente pela distância entre duas classes de origem e pela distância entre duas classes de destino, como vimos. Para a cor, basta multiplicar o coeficiente pela distância entre duas classes de destino. Como a distância máxima entre 
classes (de origem e de destino) é 1 e o parâmetro de associação origem-destino é duas vezes maior do que o da dummy de brancos, temos que, em contrastes de classes de origem cuja distância absoluta é maior ou igual a 0,5 , o peso da origem vai ser maior do que o da cor; no contraste entre classes de origem com distância menor do que 0,5 , a cor tem maior influência. Na prática, isso significa que, con- trolando pela educação, a origem é mais decisiva do que a cor para as chances de mobilidade de longa distância, ao passo que, para as chances de mobilidade de curta e média distância, ser branco - e não preto - é o que pesa mais. O Gráfico 2 mostra o impacto da cor e de diferentes contrastes de origem nas chances de ser profissional ou administrador e não trabalhador manual não qualificado.

Gráfico 2

Efeitos de cor e diferentes origens nas chances de ser profissional versus trabalho manual não qualificado, homens, 1982/1996

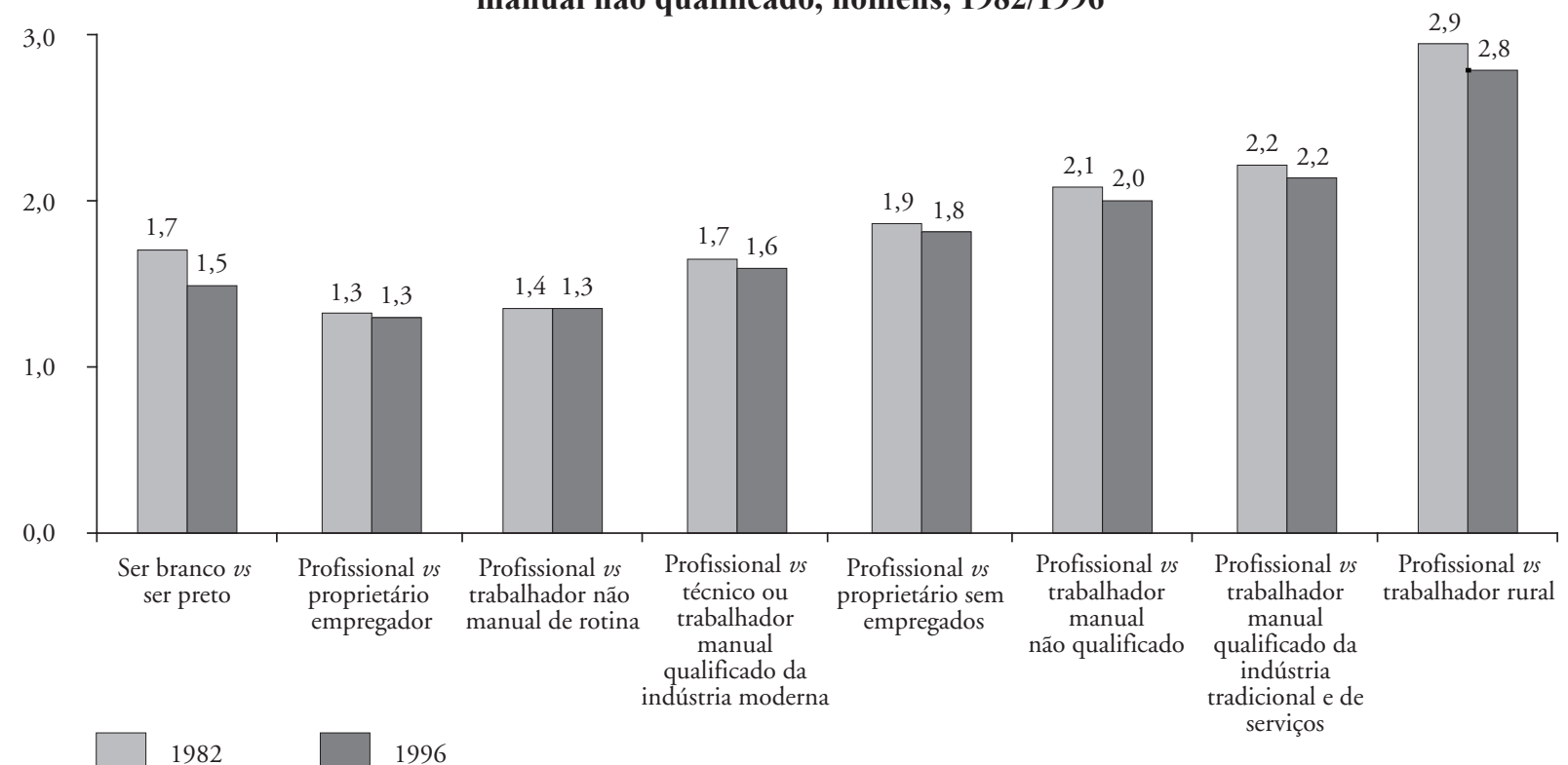

\section{Gráfico 3}

Razão de chances de ser profissional versus trabalhador não manual de rotina, por níveis educacionais (referência: nenhuma escolaridade), homens, 1982/1996

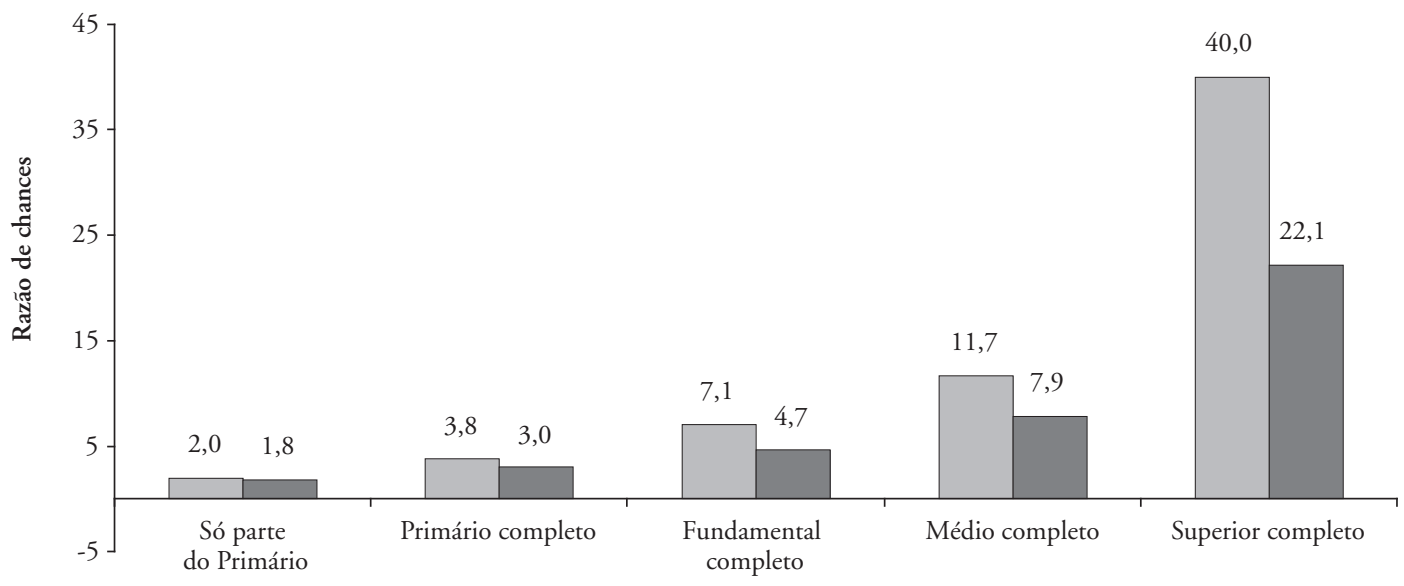


Apesar de origem e cor terem efeitos não desprezíveis, a educação é que faz diferença no modelo, como se vê no Gráfico 3. Ter nível superior vale muito, mas os retornos diminuíram expressivamente entre 1982 e 1996: se, antes, indivíduos com nível superior tinham cerca de quarenta vezes mais chances do que indivíduos sem escolaridade de serem profissionais, em vez de trabalhadores não manuais de rotina, este número caiu para 22 vezes em 1996, uma queda de 46\%. Em comparação, a queda percentual para quem tem o Ensino Médio foi de 34\%; para o Fundamental, 36\%. Ou seja, o nível superior proporcionava mais vantagens vis-àvis os outros níveis em 1982 do que em 1996.

Em suma, nossa análise indica que: a) nem na regressão linear nem no modelo LMC pudemos identificar diferenças relevantes entre brancos, pardos e pretos no que diz respeito à força da associação origem e destino e aos retornos para educação; b) nem na regressão linear nem no modelo LMC foram encontradas mudanças significativas no impacto da origem e da cor entre 1982 e 1996; c) em ambos os modelos os retornos para educação diminuíram expressivamente, sendo que na regressão a queda foi maior para os níveis intermediários e, no modelo LMC, para o nível superior; d) em ambos os casos, o peso das variáveis educacionais foi maciçamente superior aos das outras; e) no modelo LMC, cor e origem desempenham um papel relevante, sendo que a origem parece ser mais importante para a mobilidade de longa distância e a cor para a mobilidade de curta distância; f) tanto na regressão linear como no modelo LMC a diferença entre pardos e pretos é mínima, não sendo estatisticamente significativa; g) no caso da regressão linear, o processo de realização de status tornou-se mais incerto em relação às variáveis observadas ao longo do tempo.

Tudo isso implica que, em primeiro lugar, mesmo quando levamos em conta os efeitos da educação, subsiste uma influência relevante, pelo menos no modelo LMC, tanto da origem como da cor no processo de mobilidade social. Neste modelo, não é possível afirmar a primazia indiscutível seja da cor, seja da origem; da mesma maneira, é impossível reduzir um à condição de mero epifenômeno do outro. Nesse sentido, a hipótese explicativa de
Hasenbalg (1979) parece ser a mais robusta para a compreensão dos processos de mobilidade entre os homens. Mais ainda, os resultados apontam para a necessidade de abrir a "caixa preta" que envolve essas duas variáveis e descobrir com mais precisão os mecanismos pelos quais seu efeito se concretiza.

Em segundo lugar, fica claro o peso enorme da educação formal, em particular do diploma de nível superior. Parece ser fundamental, portanto, estudar os impactos da cor e da origem nas trajetórias escolares. Embora haja uma longa literatura que detecta uma influência considerável da cor nas chances de completar as diversas transiçōes escolares (ver Silva e Souza, 1986; Hasenbalg e Silva, 1992, 1999), os trabalhos que cotejam especificamente os efeitos da cor e da origem e avaliam sua variação ao longo do tempo são menos numerosos. $\mathrm{O}$ aprofundamento de pesquisas desse tipo parece ser uma via promissora para uma melhor compreensão da mobilidade social no Brasil.

De todo modo, o contraste entre indivíduos com nível superior e mesmo os que completaram o Ensino Médio é tão grande que corrobora uma interpretação menos pessimista da queda nos retornos para educação: menos do que um retrocesso das variáveis mais "meritocráticas", por assim dizer, arriscamo-nos a concluir que o que se passou foi a erosão de rents elevados que os portadores de nível superior usufruíam no mercado de trabalho do início dos anos de 1980.

\section{Fluidez e mobilidade social das mulheres}

Para trabalharmos com a mobilidade social feminina, é preciso cuidados, tendo em vista que a inserção das mulheres no mercado de trabalho mudou profundamente entre 1982 e 1996. Por exemplo, em 1982, a renda média horária da ocupação principal das mulheres correspondia a apenas $65 \%$ da dos homens; já em 1996, era 80\%. Esta convergência se mantém quando examinamos a evolução por classe: em quase todas, a renda real das mulheres cresceu mais do que a dos homens.

A partir desse pano de fundo, podemos prosseguir para a análise da regressão linear. $\mathrm{O}$ melhor modelo foi o mesmo dos homens e está detalhado 
na Tabela 6. Assim como para os homens, interações entre cor e educação, cor e origem e a introdução de variáveis como região, experiência e idade não foram relevantes.

Entre os homens, o ajuste do modelo tinha piorado $12 \%$ no período em questão; para as mulheres, a queda foi proporcionalmente similar, cerca de $11 \%$. Contudo, é preciso ressaltar que tanto em 1982 como em 1996 o modelo funciona melhor para mulheres do que para homens, ou seja, as variáveis incluídas explicam de forma mais precisa o processo de realização de status para elas.

Também como entre os homens, apenas os coeficientes educacionais e para área urbana apresentam variação estatisticamente significativa, havendo diminuição dos retornos para todos os níveis educacionais, especialmente para os intermediários e inferiores. Vale observar, no entanto, que em 1982 os retornos educacionais eram muito mais fortes para as mulheres em todos os níveis e, em 1996, em quase todos os níveis. Ter completado o Ensi- no Médio, em especial, traz retornos cerca de $50 \%$ maiores para mulheres do que homens nos dois anos em questão. Aliás, o contraste entre ter o Ensino Médio e ter nível superior varia bastante: para as mulheres, o retorno predito do diploma universitário era, em 1982, apenas $27 \%$ maior do que o do Ensino Médio e, em 1996, 50\%; para os homens; por outro lado, o contraste é bem maior, com retornos entre 74\% (1982) e 104\% (1996) maiores. Ou seja, embora a queda percentual do retorno predito para o Ensino Médio tenha sido bem maior do que a do Ensino Superior, há que se observar que o fenômeno é mais agudo entre homens do que entre mulheres. Para estas, mesmo o diploma do Ensino Médio ainda guarda um poder bastante razoável de distinção.

Em certa medida, a manutenção da segmentação do mercado de trabalho por gênero parece ser um elemento explicativo potencialmente útil, uma vez que a) se o mercado de trabalho fosse "cego" com relação ao gênero, a tendência seria de con-

Tabela 6

Modelo proposto da regressão de status attainment para mulheres

\begin{tabular}{lllll}
\hline & $\mathbf{1 9 8 2}$ & & $\mathbf{1 9 9 6}$ & \\
\hline & Coeficientes & Erro padrão & Coeficiente & Erro padrão \\
\hline Constante & 16,73 & 0,34 & 15,26 & 0,45 \\
\hline Isei do pai & 0,05 & 0,01 & 0,06 & 0,01 \\
\hline Brancos & 3,41 & 0,31 & 2,87 & 0,40 \\
\hline Pardos & 2,27 & 0,31 & 2,46 & 0,40 \\
\hline Área urbana & 2,27 & 0,22 & 3,99 & 0,25 \\
\hline Só fez parte do primário & 4,34 & 0,25 & 1,40 & 0,32 \\
\hline Primário & 10,36 & 0,25 & 5,46 & 0,29 \\
\hline Ensino Fundamental & 18,20 & 0,41 & 12,11 & 0,39 \\
\hline Ensino Médio & 32,21 & 0,34 & 25,56 & 0,35 \\
\hline Ensino Superior & 40,93 & 0,44 & 38,29 & 0,44 \\
\hline $\mathrm{R}^{2}$ ajustado & 0,607 & & 0,546 & \\
\hline $\begin{array}{l}\mathrm{R}^{2} \text { ajustado, modelo com } \\
\text { educação omitida }\end{array}$ & 0,308 & & 0,248 & \\
\hline $\begin{array}{l}\mathrm{R}^{2} \text { ajustado, modelo apenas } \\
\text { com educação }\end{array}$ & 0,600 & & 0,535 & \\
\hline
\end{tabular}


vergência dos retornos educacionais em todos os níveis e b) se a discriminação de gênero operasse no mercado de trabalho simplesmente no sentido de tornar mais difícil o acesso das mulheres às posiçōes mais altas, a tendência seria de que os retornos para educação fossem menores para elas do que para os homens.

Quando controlamos pela cor e educação, o peso da origem social entre homens é duas vezes maior do que entre mulheres tanto em 1982 como em 1996. Com efeito, a influência da origem, neste caso, parece ser pequena para as mulheres. Se a origem desempenha qualquer papel na realização de status feminina, portanto, este parece ser essencialmente indireto, via trajetória escolar. Já a cor ou raça, por outro lado, tem efeito mais pronunciado entre mulheres do que entre homens, ainda que não esteja perto de rivalizar com o componente educacional. O que mais chama a atenção, no entanto, é o fato de que, para as mulheres, a dicotomia brancos versus não-brancos não é tão justificável no que diz respeito a modelos de status attainment: de um lado, não é possível identificar diferenças entre mulheres brancas e pardas, de outro, há sim um contraste significativo entre pardas e pretas.

Partindo para a segunda etapa da análise, temos na Tabela 7 as estatísticas de ajuste de uma série de modelos LMC. Nesta análise o modelo 2 apresenta o melhor ajuste, assim como ocorre para os homens (ver Tabela 4).

Mais uma vez, optamos por reunir os dados em um único banco e utilizar variáveis dummy e

Tabela 7

Estatísticas de ajuste do modelo LMC para mulheres

1982

\begin{tabular}{|c|c|c|c|c|}
\hline & Log-Likelihood & $\mathrm{L}^{2}$ vs modelo 7 & Df vs modelo 7 & BIC \\
\hline 1. Quasi-eqRC2 & -26658 & 9657 & 21 & 9412 \\
\hline 2. Brancos, pardos e educação & -21869 & 77 & 14 & -86 \\
\hline 3. Interação origem/brancos & -21868 & 76 & 13 & -76 \\
\hline 4. Interação origem/pardos & -21859 & 59 & 12 & -81 \\
\hline 5. Interação brancos/educação & -21840 & 20 & 7 & -62 \\
\hline 6. Interação pardos/educação & -21830 & 1 & 2 & -23 \\
\hline $\begin{array}{l}\text { 7. Interação origem/ensino médio completo } \\
\text { e origem/nível superior completo }\end{array}$ & -21830 & - & - & - \\
\hline
\end{tabular}

1996

\begin{tabular}{lllll}
\hline & Log-Likelihood & L2 vs modelo 6 & Df vs modelo 6 & BIC \\
\hline 1. Quasi-eqRC2 & -29115 & 8759 & 21 & 8512 \\
\hline 2. Brancos, pardos e educação & -24761 & 51 & 14 & -114 \\
\hline 3. Interação origem/brancos & -24761 & 50 & 13 & -102 \\
\hline 4. Interação origem/pardos & -24759 & 46 & 12 & -95 \\
\hline 5. Interação brancos/educação & -24743 & 15 & 7 & -68 \\
\hline $\begin{array}{l}\text { 6. Interação pardos/educação } \\
\text { 7. Interação origem/ensino médio completo } \\
\text { e origem/nível superior completo }\end{array}$ & -24740 & 9 & 2 & -15 \\
\hline
\end{tabular}


interaçōes para dar conta de possíveis mudanças temporais nos parâmetros estimados. O Gráfico 4 contém a escala eqRC2 para as mulheres.

A diferença mais imediatamente perceptível em relação à escala para homens é que a classe de trabalhadores manuais qualificados da indústria tradicional e serviços não só aparece à frente dos trabalhadores manuais não qualificados como também fica muito próxima dos proprietários sem empregados. Além disso, cabe notar que a diferença que separa os profissionais e administradores das demais classes é menor para mulheres do que para homens e que os trabalhadores não manuais de rotina aparecem ligeiramente à frente dos proprietários empregadores.

$\mathrm{Na}$ Tabela 8 temos os resultados detalhados do modelo. No que diz respeito ao primeiro painel, mais uma vez as trabalhadoras rurais são as que têm maior propensão à imobilidade, sendo que esta propensão aumentou de forma estatisticamente significativa. Assim como para os homens, em 1982 a imobilidade das profissionais e administradoras era nula, uma vez que levamos em conta a cor e a educação; contudo, em 1996 o parâmetro aumentou expressivamente. $\mathrm{Na}$ prática, isso significa que, pelo menos para as mulheres, a tendência à imobilidade na classe mais privilegiada de nossa hierarquia cresceu entre 1982 e 1996.

Quanto à dinâmica da associação origem-destino, é preciso ter em mente, em primeiro lugar, que não podemos comparar diretamente os parâmetros estimados para as mulheres com os dos homens, uma vez que as escalas eqRC2 dos dois modelos são diferentes. Assim como entre os homens, o parâmetro de associação tem uma queda brutal 80\% em 1982, 90\% em 1996 - quando introduzimos as outras variáveis independentes. No entanto, ao contrário do que verificamos anteriormente, entre as mulheres houve uma diminuição forte da força da associação, mesmo controlando por cor e educação.

Por fim, no painel D, temos os efeitos das demais variáveis. Repetindo o que verificamos anteriormente, os efeitos da cor não diminuem entre 1982 e 1996. Também não é possível apontar diferenças relevantes entre pardos e pretos, ao contrário do que havíamos encontrado na regressão linear. De todo modo, o contraste entre mulheres brancas e pretas tem intensidade similar ao contraste entre homens brancos e pretos.

\section{Gráfico 4 \\ Escala eqRC2 para mulheres, 1982/1996}

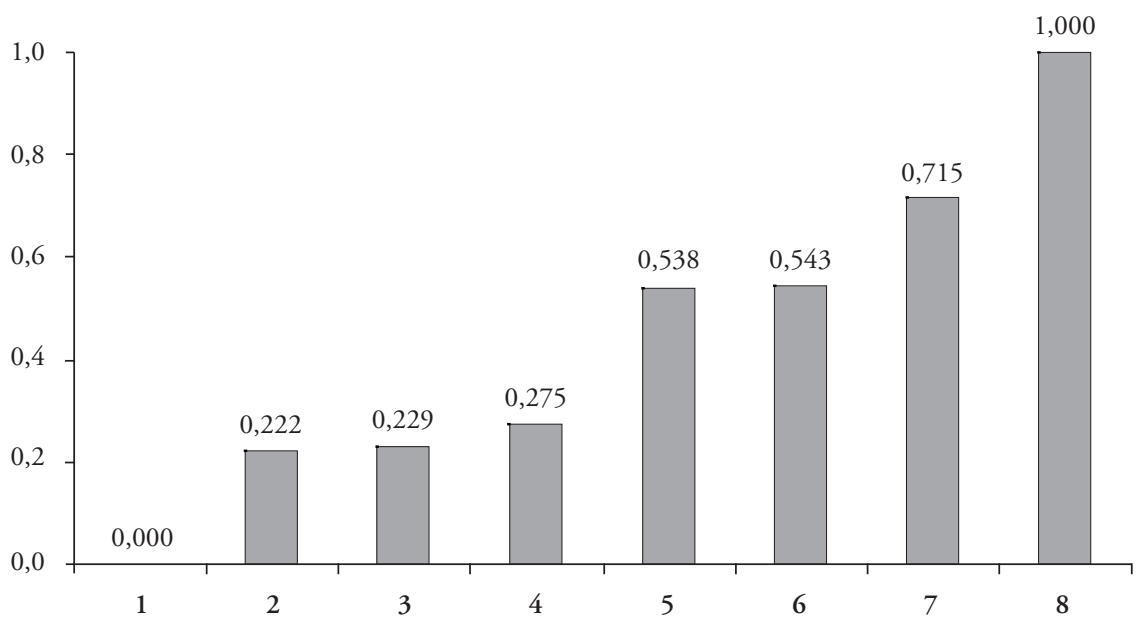

Obs.: 1 - Profissionais e administradores; 2 - Trabalhadores não manuais de rotina; 3 - Proprietários empregadores; 4 - Técnicos e supervisores do trabalho manual e trabalhadores manuais qualificados da indústria moderna; 5 - Proprietários sem empregados; 6 - Trabalhadores manuais qualificados da indústria tradicional e serviços; 7 - Trabalhadores manuais não qualificados; 8 - Proprietários rurais, produtores agrícolas autônomos e trabalhadores rurais em geral. 


\section{Tabela 8}

Parâmetros do modelo LMC para mulheres, 1982/1996

\section{A: Imobilidade em 1982}

\begin{tabular}{lll}
\hline & Coeficiente & Erro padrão \\
\hline Profissionais e administradores & $0,042^{*}$ & 0,103 \\
\hline Trabalhadores não manuais de rotina & $0,011^{*}$ & 0,086 \\
\hline Proprietários empregadores & 0,706 & 0,179 \\
\hline $\begin{array}{l}\text { Técnicos e supervisores do trabalho manual e trabalhadores } \\
\text { manuais qualificados da indústria moderna }\end{array}$ & 0,698 & 0,224 \\
\hline $\begin{array}{l}\text { Proprietários sem empregados } \\
\text { Trabalhadores manuais qualificados da indústria tradicional } \\
\text { e dos serviços }\end{array}$ & 0,446 & 0,149 \\
\hline Trabalhadores manuais não qualificados & 0,428 & 0,069 \\
\hline Trabalhadores rurais & 0,304 & 0,059 \\
\hline
\end{tabular}

B: Imobilidade em 1996

\section{Coeficiente Erro padrão}

\begin{tabular}{lll}
\hline Profissionais e administradores & 0,738 & 0,094 \\
\hline Trabalhadores não manuais de rotina & $-0,134^{*}$ & 0,076 \\
\hline Proprietários empregadores & 1,330 & 0,161 \\
\hline $\begin{array}{l}\text { Técnicos e supervisores do trabalho manual e trabalhadores } \\
\text { manuais qualificados da indústria moderna }\end{array}$ & $0,176^{*}$ & 0,237 \\
\hline Proprietários sem empregados & 0,879 & 0,114 \\
\hline $\begin{array}{l}\text { Trabalhadores manuais qualificados da indústria tradicional } \\
\text { e dos serviços }\end{array}$ & $-0,076^{*}$ & 0,071 \\
\hline Trabalhadores manuais não qualificados & 0,116 & 0,054 \\
\hline Trabalhadores rurais & 1,793 & 0,066 \\
\hline
\end{tabular}

\section{C: Associação origem-destino}

\section{Coeficiente Erro Padrão}

\begin{tabular}{lll}
\hline Associação geral & 1,136 & 0,182 \\
\hline Associação/ano & $-0,708$ & 0,240 \\
\hline
\end{tabular}




\section{D: Demais variáveis independentes}

\begin{tabular}{lll}
\hline & Coeficiente & Erro padrão \\
\hline Brancos & $-0,968$ & 0,139 \\
\hline Brancos/ano & $0,289^{*}$ & 0,207 \\
\hline Pardos & $-0,025^{*}$ & 0,141 \\
\hline Pardos/ano & $0,063^{*}$ & 0,209 \\
\hline Só fez parte do primário & $-2,800$ & 0,116 \\
\hline Só fez parte do primário/ano & 0,973 & 0,175 \\
\hline Completou o primário & $-5,203$ & 0,125 \\
\hline Completou o primário/ano & 1,228 & 0,175 \\
\hline Completou o ensino fundamental & $-8,408$ & 0,189 \\
\hline Completou o ensino fundamental/ano & 1,929 & 0,241 \\
\hline Completou o Ensino Médio & $-12,093$ & 0,198 \\
\hline Completou o Ensino Médio/ano & 1,919 & 0,244 \\
\hline Nível superior completo & $-17,094$ & 0,320 \\
\hline Nível superior completo/ano & 1,788 & 0,379 \\
\hline Ano & $0,239^{*}$ & 0,306 \\
\hline
\end{tabular}

*Não significativo a 0,05 .

\section{Gráfico 5}

Efeitos de cor e diferentes origens nas chances de ser profissional versus trabalho manual não qualificado, mulheres, 1982/1996

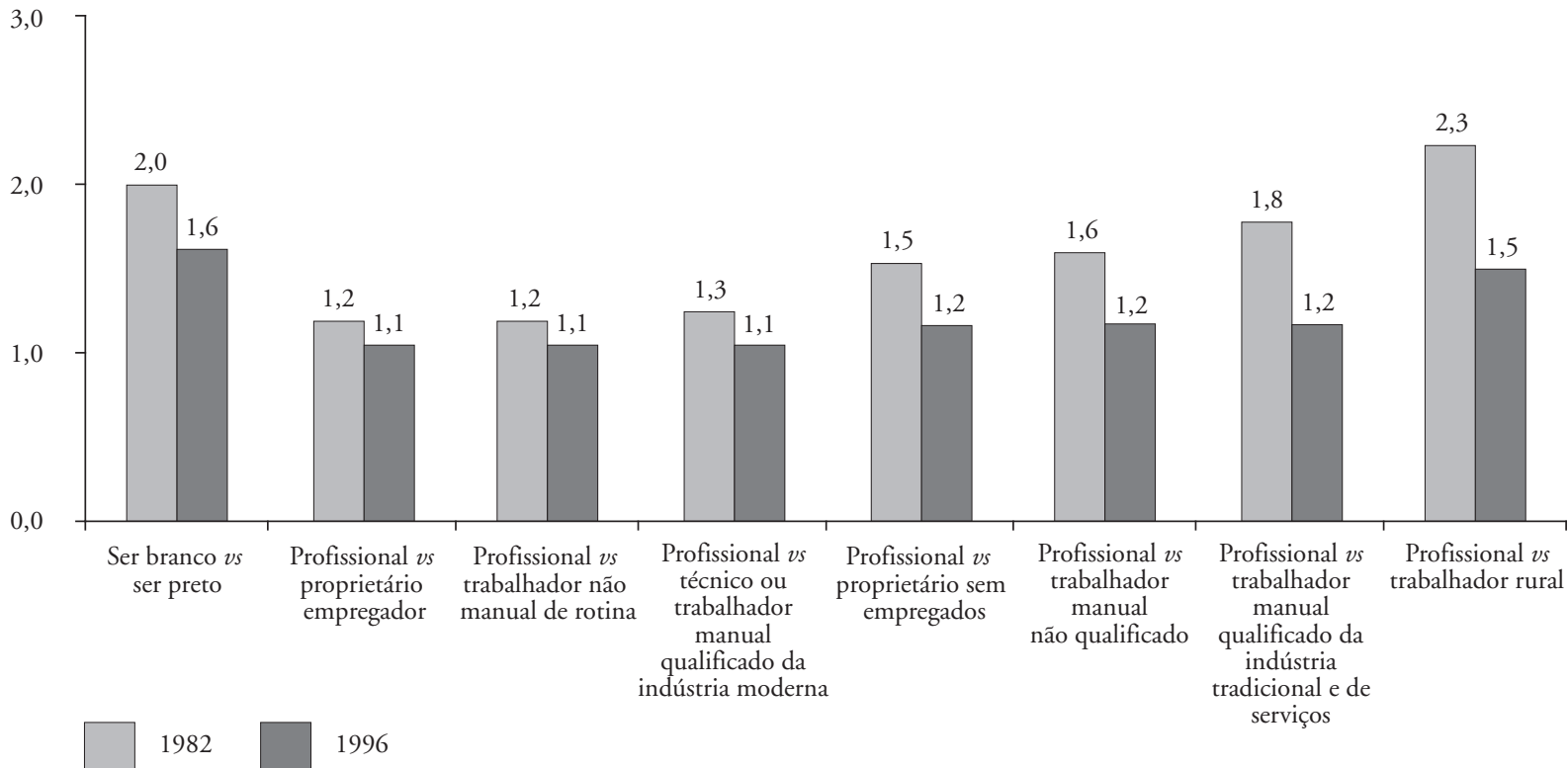


Com relação à cor e à origem, reproduzimos abaixo o mesmo gráfico que fizemos para homens. Desta vez, vemos que, controlando pela educação, a cor é inequivocamente mais importante do que a origem social. Em 1982, apenas o contraste entre filhas de profissionais e administradores e filhas de trabalhadores rurais é mais forte do que o contraste entre brancas e pretas; em 1996, nem isso. Vale notar que os dados nada dizem sobre o efeito relativo da cor e da origem sobre a trajetória escolar.

No Gráfico 6, observamos que a educação tem grande impacto, embora os retornos tenham diminuído. Em 1982, mulheres com nível superior tinham 44 vezes mais chances do que mulheres sem nenhuma escolaridade de serem profissionais em comparação com trabalhadoras não manuais de rotina, o que caiu para 30 vezes em 1996, um decréscimo de 33\%. Os retornos para o Ensino Fundamental e o Ensino Médio caíram quase na mesma proporção (35\%). Por sua vez, os níveis mais básicos recuaram menos: queda de $19 \%$ para quem fez apenas parte do primário e $24 \%$ para quem completou o primário.

Assim, também no modelo LMC a educação traz mais retornos para mulheres do que para ho- mens, pelo menos no que diz respeito aos níveis educacionais mais avançados. Além disso, vemos que este modelo contradiz os achados da regressão linear: nesta, a diferença entre o diploma universitário e o do Ensino Médio é menor entre mulheres do que entre homens, mas os resultados do modelo LMC são mais ambíguos, sugerindo uma maior similaridade por gênero.

Resumindo, podemos dizer que: a) tampouco entre mulheres pudemos identificar quaisquer diferenças significativas por cor dos retornos para educação ou da associação origem-destino; b) apesar de todas as diferenças existentes na inserção ocupacional de homens e mulheres, os modelos que melhor se ajustaram aos dados foram os mesmos para ambos, tanto na regressão linear como no modelo LMC; c) o impacto da cor não variou de forma significativa entre 1982 e 1996; d) os retornos para educação também diminuíram bastante para as mulheres, sendo que, mais uma vez, na regressão linear as maiores quedas se deram nos níveis mais básicos, e, no modelo LMC, nos níveis mais avançados; e) mesmo quando levamos em conta a queda nos retornos educacionais, ainda assim verificamos uma diminuição expressiva na associação

\section{Gráfico 6}

\section{Razão de chances de ser profissional versus trabalhador não manual de rotina, por níveis educacionais (referência: nenhuma escolaridade), mulheres, 1982/1996}

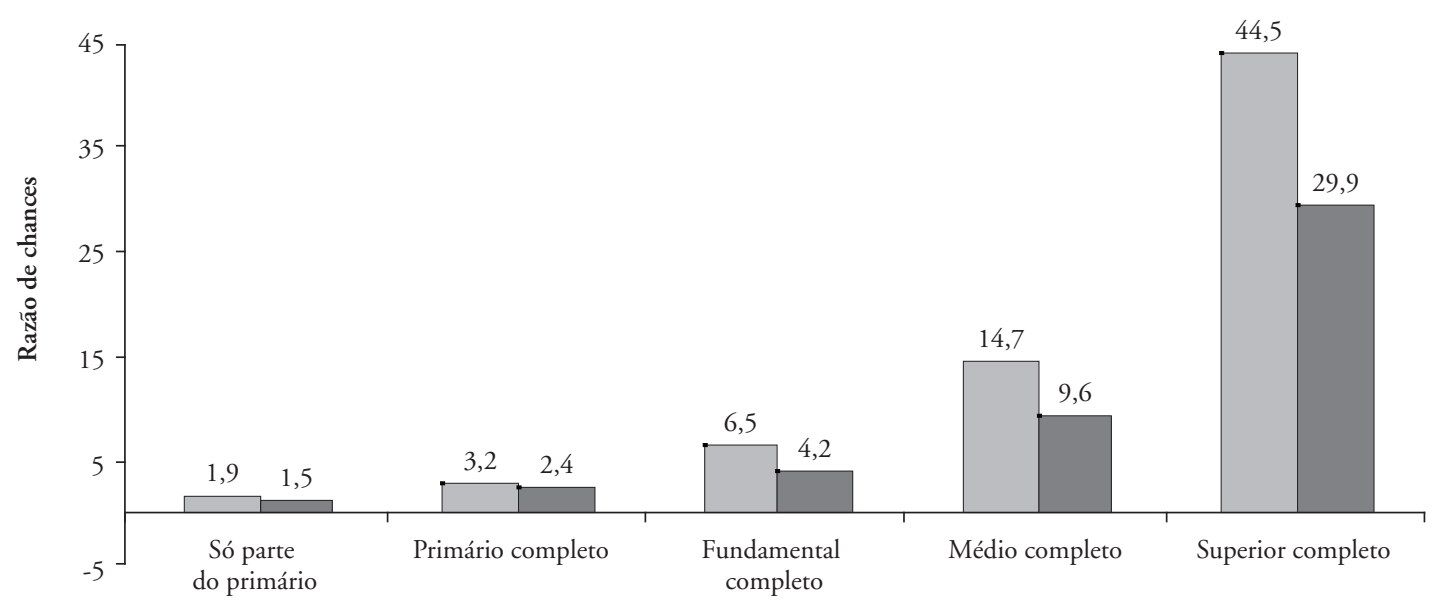


origem-destino entre mulheres; f) quando controlamos pelo nível educacional, a cor parece ser uma variável muito mais importante do que a origem social para prever a classe de destino das mulheres; g) há ambigüidades quanto à possibilidade de separarmos mulheres brancas e não-brancas em uma dicotomia rígida; h) conforme vimos no modelo de regressão linear, também entre mulheres o processo de realização de status tornou-se mais incerto entre 1982 e 1996.

\section{Conclusão}

Em todos os modelos, a educação aparece como principal determinante da mobilidade social, com impacto muito mais forte do que o da classe de origem ou raça. A diminuição significativa dos retornos educacionais entre 1982 e 1996 é, sem dúvida, o resultado mais robusto e significativo deste trabalho. No caso dos homens, esta diminuição responde sozinha por todo o aumento da fluidez social no período; entre as mulheres, houve também uma queda na associação origem-destino, mas cuja importância é secundária em função do grande peso da educação.

Tal fenômeno pode, em tese, ser avaliado de maneira díspare: negativamente, como enfraquecimento da variável mais meritocrática do nosso modelo, ou, positivamente, como erosão de rents usufruídos por portadores de diploma em um contexto de baixa escolaridade média. Diante do abismo brutal que ainda separa indivíduos com ensino superior completo dos demais, esta segunda interpretação nos parece mais adequada.

Os resultados apresentados também nos permitem reafirmar que o padrão de mobilidade realmente não parece variar por gênero; no máximo, podese dizer que a educação é um elemento com poder de distinção ainda maior entre as mulheres do que entre os homens. Da mesma maneira, também não há diferenças significativas no padrão de brancos, pardos e pretos, uma vez que nem os retornos à educação nem a associação entre origem e destino variam por cor ou raça. Tampouco pudemos detectar interaçóes relevantes entre origem de classe e níveis educacionais específicos. Assim, tanto cor como classe parecem ter apenas um efeito direto razoavelmente estável - sobretudo no caso dos homens -, mas definitivamente menos importante do que o da educação. Na comparação entre ambos, temos que, para os homens, a cor tem maior efeito na mobilidade de curta distância e a origem, na de longa; entre as mulheres, a cor é sempre mais importante. Entre elas, aliás, o agrupamento de pardos e pretos na categoria "não-brancos" parece menos apropriado do que entre os homens.

Dentre as quatro hipóteses anteriormente mencionadas sobre a relação entre classe, raça e mobilidade, portanto, os resultados são mais compatíveis com aquela que prevê que barreiras de classe e raça são mutuamente irredutíveis e relativamente independentes entre si, não havendo nenhuma tendência inexorável para o enfraquecimento da desigualdade racial. O que se pode acrescentar, no entanto, é que provavelmente vale mais a pena enfatizar o efeito dessas variáveis na trajetória educacional dos indivíduos do que insistir nas desvantagens cumulativas propriamente ditas, isto é, nas desigualdades de oportunidades existentes entre indivíduos de características educacionais semelhantes. Isso obviamente não quer dizer que tais desvantagens inexistam, mas sim que, diante do papel preponderante da educação, faz-se necessária uma investigação muito mais aprofundada dos determinantes do sucesso educacional, o que necessariamente envolve a consideração da classe de origem e da cor ou raça dos indivíduos.

Portanto, por mais que a retórica da "educação como forma de vencer na vida" seja muitas vezes usada como pura cortina de fumaça ideológica, é preciso admitir também a possibilidade de que os estudos sociológicos sobre mobilidade social no Brasil - e quiçá no mundo - talvez tenham se concentrado excessivamente na análise de tabelas bivariadas de origem e destino, muito embora já na década de 1970 Langoni (1973) defendesse a idéia de que as desigualdades educacionais eram as principais causas da extrema desigualdade no Brasil. Nesse sentido, talvez seja hora de recuar um pouco e levar a sério a idéia de que o cerne da geração e da reprodução das desigualdades de oportunidades em nosso país está em "uma luta de classes que não se dá nos pátios das montado- 
ras de automóveis do ABC paulista, como muitos pensavam, e sim no desenho de nosso sistema educacional" (Ferreira, 2000).

\section{Notas}

1 A Pnad incluiu perguntas específicas sobre mobilidade social em apenas quatro ediçôes, 1973, 1982, 1988 e 1996. O período entre 1982 e 1996 foi escolhido por três motivos: primeiro, trata-se de um intervalo de tempo apropriadamente longo; segundo, em 1982 a intensa mobilidade estrutural dos anos de 1960 e 1970 já tinha arrefecido, mas a crise dos anos de 1980 ainda não tinha se manifestado com toda sua força; terceiro, 1996 é o último ano para o qual temos informaçôes na Pnad e representa um momento pós-Plano Real e pós-hiperinflação.

2 Algumas das críticas à conceitualização funcionalista da estratificação social incluem as de Wrong (1959, 1964), Dahrendorf (1964) e Tumin (1994). Para críticas específicas aos métodos e pressupostos da tradição do status attainment, ver Hodge (1981), Marshall et al. (1988), Erikson e Goldthorpe (1992) e Breen e Rottman (1995).

3 Para descrições mais minuciosas da produção nacional, ver Silva (1999), Ribeiro (2007), Souza (2007), entre outros. Para revisões bibliográficas específicas sobre mobilidade e a questão racial, ver Osório (2004, 2009) e Ribeiro (2006).

4 Segundo o último Censo do IBGE, as regiōes Nordeste e Sudeste, juntas, abrigavam, em 2000, 70,8\% da população brasileira.

5 A consistência interna da tipologia de classes de Goldthorpe foi testada por Evans (1992), com resultados positivos. Uma comparação empírica entre o esquema neoweberiano de Goldthorpe e a primeira versão da tipologia neomarxista de Wright, bastante favorável ao primeiro, pode ser encontrada em Marshall et al. (1988).

6 Como as ocupaçôes que entram em cada classe são as mesmas em 1982 e 1996 e o Isei delas também é o mesmo, não há variação relevante entre os dois anos.

7 Para exposições mais longas acerca das propriedades matemáticas dos modelos SOR e RC2, ver também Hendrickx e Ganzeboom (1998), Hendrickx (2000) e Dessens et al. (2003).

8 Embora utilizemos esta terminologia, vale lembrar que a antiga divisão entre "primário" e "ginásio" há muito não existe mais. Atualmente, desde a promul- gação da Lei de Diretrizes e Bases da Educação, em 1996, o sistema educacional brasileiro organiza-se apenas em Ensino Fundamental (o antigo $1^{\circ}$ grau), Médio (o antigo $2^{\circ}$ grau) e Superior. No entanto, acreditamos que completar a $4^{a}$ série do Ensino Fundamental continua representando uma transição importante e, por isso, incluímos esta categoria, optando pela terminologia mais antiga ("primário") apenas para tornar o texto mais fluido.

9 O único ponto razoavelmente inesperado é o fato de trabalhadores manuais não qualificados estarem ligeiramente à frente dos trabalhadores manuais qualificados da indústria tradicional e dos serviços. No entanto, isto parece ser empiricamente válido (ver Souza, 2007).

10 Os dados para renda foram deflacionados para julho de 2008 pelo IPCA.

\section{BIBLIOGRAFIA}

ANDERSON, J. A. (1984), "Regression and ordered categorical variables (with discussion)". Journal of the Royal Statistical Society, série B, 46 (1): 1-30.

AZEVEDO, T. (1996), As elites de cor numa cidade brasileira: um estudo de ascensão social, classes sociais e grupos de prestígio. Salvador, Edufba.

BARROS, R. P.; CARVALHO, M.; FRANCO, S. \& MENDONÇA, R. (2006a), "A queda recente da desigualdade de renda no Brasil", in R. P. Barros, M. N. Foguel e G. Ulyssea (orgs.), Desigualdade de renda no Brasil: uma análise da queda recente. Brasília, Ipea, vol. 1.

BARROS, R. P.; FRANCO, S. \& MENDONÇA, R. (2006b), "A recente queda na desigualdade de renda e o acelerado progresso educacional brasileiro da última década", in R. P. Barros, M. N. Foguel e G. Ulyssea (orgs.), Desigualdade de renda no Brasil: uma análise da queda recente. Brasília, Ipea, vol. 2.

BARROS, R. P.; CARVALHO, M.; FRANCO, S. \& MENDONÇA, R. (2006c), "Determinantes imediatos da queda da desigualdade de renda brasileira", in R. P. Barros, M. N. Foguel e G. Ulyssea (orgs.), Desigualdade de renda no Brasil: uma análise da queda recente. Brasília, Ipea, vol. 3 . 
BLAU, P. \& DUNCAN, O. D. (1967), The American occupational structure. Nova York, John Wiley \& Sons.

BREEN, R. (1994), "Individual level models for mobility tables and other cross-classifications". Sociological Methods \& Research, 33: 147-173. (ed.), (2004), Social mobility in Europe. Nova York, Oxford University Press.

BREEN, R. \& JONSSON, J. (2007), "Explaining change in social fluidity: educational equalization and educational expansion in twentiethcentury Sweden”. American Journal of Sociology, 112 (6): 1775-1810.

BREEN, R. \& LUIJKX, R. (2007), "Social mobility and education: a comparative analysis of period and cohort trends in Britain and Germany”, in S. Scherer, R. Pollak, G. Otte e M. Gangl (eds.), From origin to destination: trends and mechanisms in social stratification research, Nova York, Campus.

BREEN, R. \& ROTTMAN, D. (1995), Class Stratification: A Comparative Perspective. Londres, Harvester Wheatsheaf.

CARDOSO, A. M. (1999), Sindicatos, trabalhadores e a coqueluche neoliberal: a era Vargas acabou? Rio de Janeiro, Fundação Getúlio Vargas.

CASTRO, N. A. \& DEDECCA, C. S. (2001), "Flexibilidade e precarização: tempos mais duros", in N. Castro e C. Dedecca (orgs.), A ocupação na América Latina: tempos mais duros, São Paulo/Rio de Janeiro, Associação Latino Americana de Sociologia do Trabalho.

COSTA PINTO, L. (1952), O negro no Rio de Janeiro: relaçôes de raça numa sociedade em mudança. São Paulo, Companhia Editora Nacional.

DAHRENDORF, R. (1964), "Out of utopia: toward a reorientation of sociological analysis", in L. Coser e B. Rosenberg (orgs.), Sociological theory: a book of readings, Londres, CollierMacMillan.

DESSENS, J. A. G.; JANSEN, W.; GANZEBOOM, H. B. G. \& VAN DER HEIJDEN, P. G. M. (2003), "Patterns and trends in occupational attainment of first jobs in the Netherlands, 1930-1995: ordinary least squares regression versus conditional multinomial lo- gistic regression". Journal of the Royal Statistical Society, 168 (1): 63-84.

DIPRETE, T. (1990), "Adding covariates to loglinear models for the study of social mobility". American Sociological Review, 55 (5): 757-773.

ERIKSON, R. \& GOLDTHORPE, J. H. (1992), The constant flux: a study of class mobility in industrial societies. Oxford, Clarendon Press.

EVANS, G. (1992), "Testing the validity of the Goldthorpe class schema”. European Sociological Review, 8: 211-232.

FERNANDES, F. (1965), A integração do negro na sociedade de classes. São Paulo, Companhia Editora Nacional.

FERREIRA, F. H. G. (2000), "Os determinantes da desigualdade de renda no Brasil: luta de classes ou heterogeneidade educacional?", in R. Henriques (org.), Desigualdade e pobreza no Brasil, Rio de Janeiro, Ipea.

FERREIRA, F. H. G. \& BARROS, R. P. (1998), "Climbing a moving mountain: explaining the decline in income inequality in Brazil from 1976 to 1996 ". Trabalho apresentado em First Workshop of the Lacea/IDB/World Bank Inequality and Poverty Network, Buenos Aires.

FERREIRA, F. H. G. \& LITCHFIELD, J. (2001), "Education or inflation? The micro and macroeconomics of the Brazilian income distribution during 1981-1995". Cuadernos de Economía, 38 (114): 209-238.

FERREIRA, F. H. G.; LEITE, P. G.; LITCHFIELD, J. A. \& ULYSSEA, G. (2006), "Ascensão e queda da desigualdade de renda no Brasil". Econômica, 8 (1): 147-169.

GANZEBOOM, H. B. G.; DE GRAAF, P. \& TREIMAN, D. (1992), "A standard international socio-economic index of occupational status". Social Science Research, 21: 1-56.

GOLDTHORPE, J. H. (2000), On sociology: numbers, narratives and the integration of research and theory. Oxford, Oxford University Press.

GOODMAN, L. (1979), "Simple models for the analysis of association on cross-classifications having ordered categories". Journal of the American Statistical Association, 74: 537-552.

HASENBALG, C. (1979), Discriminação e desigualdades raciais no Brasil. Rio de Janeiro, Graal. 
(1988), "Raça e mobilidade social", in C. Hasenbalg e N. V. Silva (eds.), Estrutura social, mobilidade e raça, Rio de Janeiro, Iuperj/ Vértice.

HASENBALG, C. \& SILVA, N. V. (eds.). (1988), Estrutura social, mobilidade e raça. Rio de Janeiro, Iuperj/Vértice.

(1992), Relaçôes raciais no Brasil contemporâneo. Rio de Janeiro, Rio Fundo Editora. (1999), "Educação e diferenças raciais na mobilidade ocupacional no Brasil", in C. Hasenbalg, N. V. Silva e M. Lima, Cor e estratificação social, Rio de Janeiro, Contracapa.

HENDRICKX, J. (2000), "Special restrictions in multinomial logistic regression". Stata Technical Bulletin, 56: 18-26.

HENDRICKX, J. \& GANZEBOOM, H. B. G. (1998), "Occupational status attainment in the Netherlands, 1920-1990: a multinomial logistic analysis". European Sociological Review, 14 (4): 387-403.

HODGE, R. W. (1981), "The measurement of occupational status". Social Science Research, 10: 396-415.

HOUT, M. (1988), "More universalism, less structural mobility: the American occupational structure in the 1980s". American Journal of Sociology, 93 (6): 1358-1400.

HOUT, M \& HAUSER, R. (1992), "Symmetry and hierarchy in social mobility: a methodological analysis of the Casmin model of class mobility". European Sociological Review, 9: 239-266.

LANGONI, C. G. (1973), Distribuição da renda e desenvolvimento econômico do Brasil. Rio de Janeiro, Expressão e Cultura.

LOGAN, J. (1983), "A multivariate model for mobility tables". The American Journal of Sociology, 89 (2): 324-349, set.

MARSHALL, G.; ROSE, D.; NEWBY, H. \& VOGLER, C. (1988), Social class in modern Britain. Londres, Hutchinson.

MOURA, R. L. (2008), "Testando as hipóteses do modelo de Mincer para o Brasil”. Revista Brasileira de Economia, 62 (4): 407-449

NOGUEIRA, O. (1998), Preconceito de marca: as relaçôes raciais em Itapetininga. 2 ed. São Paulo, Edusp.
OSÓRIO, R. G. (2003), Mobilidade social sob a perspectiva da distribuição de renda. Brasília, dissertação de mestrado em Sociologia, UnB. . (2004), "A mobilidade social dos negros brasileiros”. Texto para Discussão, 1033, Brasília, Ipea. (2009), A desigualdade racial de renda no Brasil: 1976-2006. Brasília, tese de doutorado em Sociologia, UnB.

PASTORE, J. \& SILVA, N. V. (2000), Mobilidade social no Brasil. São Paulo, Makron.

PIERSON, D. (1945), Brancos e pretos na Bahia: estudo de contato racial. São Paulo, Companhia Editora Nacional.

RAFTERY, A. E. (1986), "Choosing models for cross-classifications". American Sociological Review, 51 (1): 145-146.

. (1995), "Bayesian model selection in social research". Sociological Methodology, 25: 111-163.

RAMOS, L. \& VIEIRA, M. L. (2001), "Desigualdade de rendimentos no Brasil nas décadas de 80 e 90: evolução e principais determinantes". Texto para Discussão, 803, Rio de Janeiro, Ipea.

RIBEIRO, C. A. C. (2006), "Classe, raça e mobilidade social no Brasil”. Dados - Revista de Ciências Sociais, 49 (4): 833-873. . (2007), Estrutura de classe e mobilidade social no Brasil. Bauru, SP, Edusc.

RIBEIRO, C. A. C. \& SCALON, M. C. (2001), "Mobilidade de classes no Brasil em perspectiva comparada". Dados - Revista de Ciências Sociais, 44: 53-96.

RIBEIRO, C. A. C. \& TORCHE, F. (2010), "Pathways of change in social mobility: industrialization, education and growing fluidity in Brazil". Research in Social Stratification and Mobiliy.

SILVA, N. V. (1978), Black-white income differentials: Brazil, 1960. Michigan, Ann Arbor.

(1988), "Cor e processo de realização socioeconômica”, in C. Hasenbalg e N. V. Silva (eds.), Estrutura social, mobilidade e raça, Rio de Janeiro, Iuperj/Vértice. (1999), "Mobilidade social", in S. Miceli (org.), O que ler na ciência social brasileira 
(1970-1995), São Paulo/Brasília, Sumaré/Anpocs/Capes, vol. 2. . (2003), "O esquema analítico e a classificação ocupacional”, in C. Hasenbalg e N. V. Silva (orgs.), Origens e destinos: desigualdades sociais ao longo da vida, Rio de Janeiro, Topbooks. . (2007), "Prefácio", in C. A. C. Ribeiro, Estrutura de classe e mobilidade social no Brasil, Bauru, SP, Edusc.

SILVA, N. V. \& SOUZA, A. M. (1986), "Um modelo para análise da estratificação educacional no Brasil". Cadernos de Pesquisa, 58: 40-57, Fundação Carlos Chagas.

SORENSEN, A. (2005), "Foundations of a rentbased class analysis", in WRIGHT, E. O. Wright (org.), Approaches to class analysis, Cambridge, Cambridge University Press.

SOUZA, P. H. G. F. (2007), Estratificação social e mobilidade no Brasil: uma comparação teórica e empirica entre os modelos das três últimas geraçôes de estudos sobre mobilidade social. Rio de Janeiro, dissertação de mestrado em Sociologia, Iuperj.

SWIFT, A. (2004), "Would perfect mobility be perfect?”. European Sociological Review, 20 (1): $1-11$.

TREIMAN, D. \& GANZEBOOM, H. B. G. (2000), "The fourth generation of comparative stratification research", in S. Quah e A. Sales, The international handbook of sociology, Londres, Sage.

TUMIN, M. (1994), "Some principles of stratification: a critical analysis", in D. Grusky (org.), Social stratification: class, race and gender in sociological perspective, Boulder, Westview Press.

WESTERN, M. (1999), "Class attainment among British men: a multivariate extension of the Casmin model of intergenerational class mobility". European Sociological Review, 15 (4): 431-454, dez.

WRONG, D. (1959), "The functional theory of stratification: some neglected considerations". American Sociological Review, 24 (6): 772-782. . (1964), "The oversocialized conception of man in modern sociology", in L. Coser e B. Rosenberg, Sociological theory: a book of readings, Londres, Collier-MacMillan. 


\section{DESIGUALDADE DE OPORTUNIDADES NO BRASIL: CONSIDERAÇÓES SOBRE CLASSE, EDUCAÇÃO E RAÇA}

\section{Pedro Ferreira de Souza, Carlos Antonio Costa Ribeiro e Flavio Carvalhaes}

Palavras-chave: Mobilidade social; Desigualdade de oportunidades; Desigualdade racial; Análise de classes.

Este trabalho analisa os determinantes da mobilidade social de homens e mulheres no Brasil em 1982 e 1996, com base em regressões de realização de status e em modelos logísticos multinomiais condicionais. Em particular, investigamos os efeitos da origem social, da raça e da educação na desigualdade de oportunidades. A principal conclusão é de que a educação é a variável mais importante, mas cujos retornos vêm declinando rapidamente, o que explica quase todo o aumento da fluidez social no período. Raça e origem social são elementos que potencialmente determinam o sucesso educacional dos indivíduos, mas que desempenham diretamente um papel apenas secundário no mercado de trabalho. Não foram detectadas interaçóes relevantes, o que implica que os retornos para educação são semelhantes por cor ou raça. $\mathrm{O}$ padrão de mobilidade social das mulheres é basicamente o mesmo dos homens.

\section{INEQUALITY OF OPPORTUNITIES IN BRAZIL: CONSIDERATIONS ON CLASS, EDUCATION, AND RACE}

\section{Pedro Ferreira de Souza, Carlos Antonio Costa Ribeiro and Flavio Carvalhaes}

Keywords: Social mobility; Inequality of opportunities; Racial inequality; Class analysis.

This paper analyzes the determinants of social mobility for men and women in Brazil in 1982 and 1996, based on status attainment regressions and multinomial conditional logistic models. We are especially interested in the way social origins, race, and education shape inequalities of opportunities. The main result is that education is the one truly important variable, although its returns are rapidly diminishing, which accounts for almost all of the increase in social fluidity during this period. Race and social origins may play a large role in determining educational attainment, but, once in the labor market, they are of less importance. No relevant interactions were detected, which entails that returns to education do not vary by race. The patterns of social mobility are very similar for both men and women.

\section{INÉGALITÉ D'OPPORTUNITÉS AU BRÉSIL : CONSIDÉRATIONS À PROPOS DE CLASSE, D'ÉDUCATION ET DE RACE}

\section{Pedro Ferreira de Souza, Carlos Antonio Costa Ribeiro et Flavio Carvalhaes}

Mots-clés: Mobilité sociale; Inégalité d'opportunités; Inégalité raciale; Analyse de classes.

Ce travail analyse les facteurs déterminants de la mobilité sociale entre hommes et femmes au Brésil entre 1982 et 1996 , en se fondant sur des régressions de réalisations de statu et sur des modèles logistiques multinomiaux conditionnels. Nous avons recherché, en particulier, les effets de l'origine sociale, de la race et de l'éducation dans l'inégalité d'opportunités. La principale conclusion est que l'éducation est la variable la plus importante, mais dont les répercussions sont en déclin, ce qui explique pratiquement toute l'augmentation de fluidité sociale au cours de la période. Race et origine sociale sont des éléments qui, potentiellement, déterminent le succès éducationnel des individus, mais qui exercent directement un rôle uniquement secondaire sur le marché de travail. Nous n'avons pas détecté d'interaction importante, ce qui signifie que les répercussions par rapport à l'éducation sont semblables par couleur ou par race. Le modèle de mobilité sociale des femmes est fondamentalement le même que celui des hommes. 